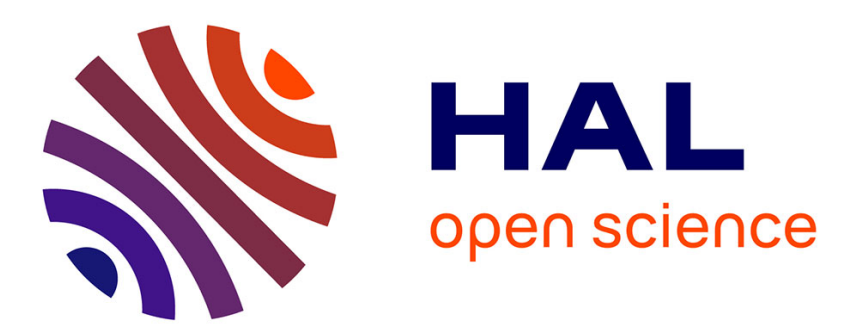

\title{
Elaboration of in situ phosphorus doped polysilicon films under LPCVD conditions : process modelling and characterization
}

\author{
A. Tounsi, E. Scheid, C. Azzaro, P. Duverneuil, J. Couderc
}

\section{- To cite this version:}

A. Tounsi, E. Scheid, C. Azzaro, P. Duverneuil, J. Couderc. Elaboration of in situ phosphorus doped polysilicon films under LPCVD conditions: process modelling and characterization. Journal de Physique IV Proceedings, 1993, 03 (C3), pp.C3-123-C3-130. 10.1051/jp4:1993315 jpa-00251372

HAL Id: jpa-00251372

https://hal.science/jpa-00251372

Submitted on 1 Jan 1993

HAL is a multi-disciplinary open access archive for the deposit and dissemination of scientific research documents, whether they are published or not. The documents may come from teaching and research institutions in France or abroad, or from public or private research centers.
L'archive ouverte pluridisciplinaire HAL, est destinée au dépôt et à la diffusion de documents scientifiques de niveau recherche, publiés ou non, émanant des établissements d'enseignement et de recherche français ou étrangers, des laboratoires publics ou privés. 


\title{
Elaboration of in situ phosphorus doped polysilicon films under LPCVD conditions: process modelling and characterization
}

\author{
A. TOUNSI, E. SCHEID*, C. AZZARO, P. DUVERNEUIL and J.P. COUDERC \\ Laboratoire de Génie Chimique, URA 192 du CNRS, ENSIGC/INPT, 18 chemin de la Loge, \\ 31078 Toulouse cedex, France \\ " LAAS-CNRS, 7 avenue du Colonel Roche, 31077 Toulouse cedex, France
}

\begin{abstract}
In this paper, results of a complete study dealing with the deposition of in situ phosphorus doped polysilicon and combining experimental approach, deposition modelling and film characterization are presented. Their interpretation has helped to put forward the importance of the entrance zone length as deposition parameter, which was most often totally neglegted.
\end{abstract}

\section{Introduction}

The properties of thin films elaborated by LPCVD are highly influenced by the interacting hydrodynamics, mass transfer and chemical reactions occurring in LPCVD reactors. As a result, this complex interaction obscures the basic underlying phenomena and often hampers the process development at industrial scale.This is the case of in situ phosphorus doped polysilicon deposition, which has for long been identified by practicians as problematic $[1,2,3,4,5,6,7,8]$, since the addition of phosphine, the doping gas, to a silane flow strongly affects the deposition phenomenon. The main difficulties encountered are, first, the drastic reduction of polysilicon growth rate and second, the presence of important across-wafer non-uniformities, creating the so-called "bull's eye effect".

This is why another study has been carried out, combining experimental approach, deposition modelling and film characterization, to provide further insight into the overall deposition process.

First, experimental results of in situ phosphorus doped polysilicon growth rate will be presented. This part has mainly contributed to recognize the importance of an often neglected part of LPCVD reactors, i.e. their hot entrance region through which concentrations of products, coming from silane pyrolysis, build up.

The implications of this original result have thus been investigated from a theoretical viewpoint to introduce an additional degree of freedom in the CVD2 model, elaborated in our laboratory and presented in great details elsewhere $[9,10]$. This adaptation of the CVD2 model will be discussed and model predictions will be compared with the experimental data.

Then, to provide the comprehension of the process in its whole, the microstructure and properties of the deposited films $\left(560^{\circ} \mathrm{C}-620^{\circ} \mathrm{C}\right)$ have been studied to characterize polysilicon layers (resistivity and $405 \mathrm{~nm}$-ellipsometry measurements). 


\section{Experimental study}

\subsection{Operating conditions}

Experiments were carried out in a conventional tubular horizontal hot-wall LPCVD reactor, in which p-type $<100>$ wafers were stacked vertically in a boat. The main characteristics of this equipment are presented in table 1.

\begin{tabular}{|c|c|}
\hline Geometrical parameters & \\
\hline Tube length [mm] & 200 \\
\hline Tube diameter [mm] & 153 \\
\hline Wafer diameter [mm] & 100 \\
\hline Interwafer distance [mm] & $9.52 / 7$ \\
\hline Wafers number & $103 / 30$ \\
\hline
\end{tabular}

Table 1 : Reactor geometry

Prior to deposition, test wafers were thermally oxidized to a thickness of $1000 \AA \mathrm{SiO}_{2}$ and were placed at selected locations along the length of the boat. In the following, the position of each wafer in the batch is numbered from the first wafer reached by the gases.

Experiments were performed at two temperatures $560^{\circ} \mathrm{C}$ and $620^{\circ} \mathrm{C}$, with a flat profile. Pressure was set at 0.25 Torr. As gaseous sources, pure silane and 5\% phosphine in nitrogen were used for in situ phosphorus doped polysilicon deposition. Silane flowrate was maintained at $235 \mathrm{sccm}$ and $3 \mathrm{sccm}$ of phosphine was injected with $57 \mathrm{sccm}$ of nitrogen. To obtain a reference undoped polysilicon layer, experiments were also carried out, with only silane and nitrogen. The same silane flowrate was used as in the doped process, only nitrogen flowrate was adjusted to maintain pressure at 0.25 Torr.

Two wafer boats, different in their reception capacity were used (respectively 103 and 30 positions) and were mounted coaxial with the furnace axis. The longer boat could therefore be positioned next to the entrance door of the reactor.

A series of experiments was achieved with varying the longitudinal location of the boat inside the reactor. This parameter (DEW) was defined as the distance separating the entrance door of the reactor and the first wafer $(\mathrm{DEW}=100 ; 805 ; 1080 \mathrm{~mm}$ ).

\subsection{Growth rate evolution}

2.2.1 Pure polysilicon deposition : Figures 1(a) and 1(b) illustrate the polysilicon growth rates, measured at the wafer centre (no across-wafer non-uniformity was observed) as function of the wafer position in the reactor for two load positions. It can be pointed out that he longitudinal variations in growth rates are quite small for the two temperatures and the difference in the evolution obtained for the two load positions are in the range of uncertainties attributed to experimental adjustments (temperature, pressure and flowrates ...). It is to be noted that an increase of $60^{\circ} \mathrm{C}$ in temperature results in an enhancement of growth rate by a factor 5 .

2.2.2 In situ phosphorus doped polysilicon deposition: The longitudinal growth rate evolution obtained in the case of in situ phosphorus doped polysilicon deposition is displayed in Figures 2(a) and 2(b) for three load positions at $620^{\circ} \mathrm{C}$. The principal information that can be deduced is following :

(i) - The addition of phosphine involves a reduction of polysilicon growth rate (by a factor 12 to 14).

(ii) -An increase in the entrance zone length results in an enhanced deposition rate.

(iii)-When the boat is positioned next to the entrance door $\left(D_{\mathrm{EW}}=100 \mathrm{~mm}\right)$, polysilicon growth rate is practically uniform along the load. 


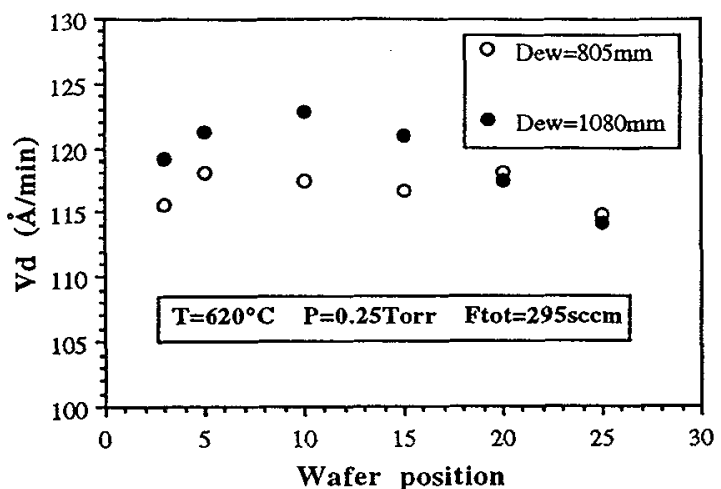

Fig.1(a): Longitudinal pure $S$ i-poly growth rate evolution $\mathrm{T}=620^{\circ} \mathrm{C} ; \mathrm{P}=0.25$ Torr $; \mathrm{Q}=295 \mathrm{sccm}$

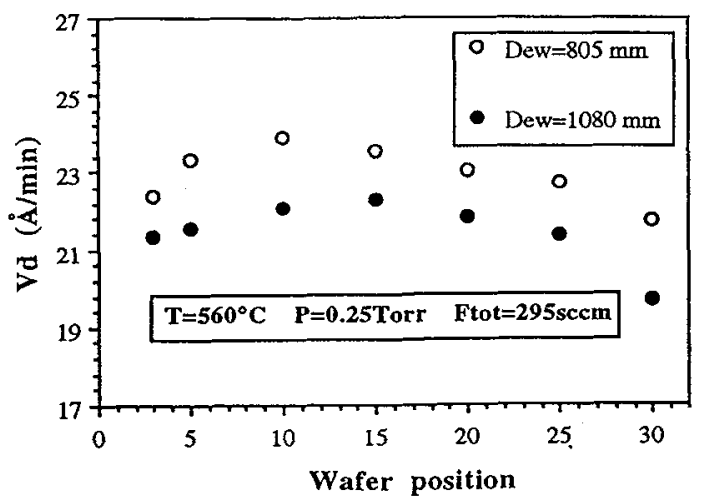

Fig.1(b): Longitudinal pure Si-poly growth rate evolution $\mathrm{T}=560^{\circ} \mathrm{C} ; \mathrm{P}=0.25$ Torr $; \mathrm{Q}=295 \mathrm{sccm}$

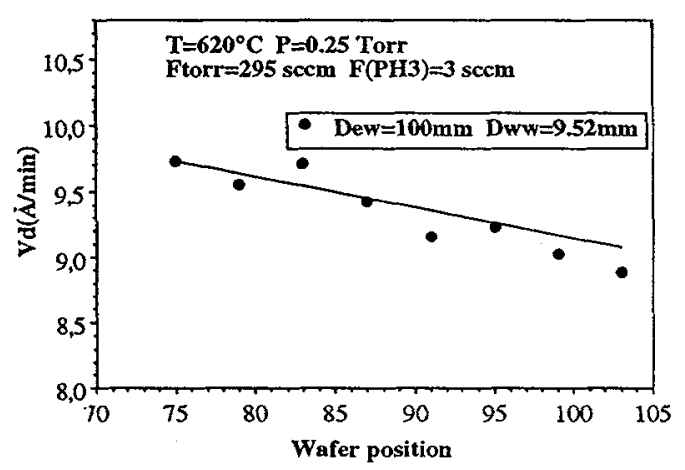

Fig.2(a): Longitudinal P-doped Si-poly growth rate evolution

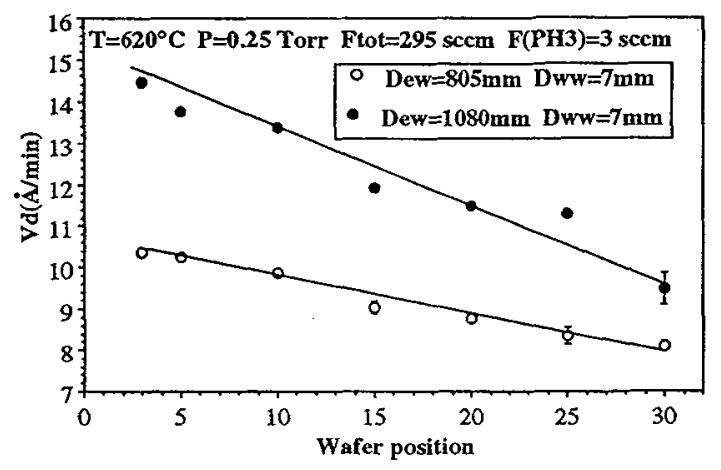

Fig.2(b): Longitudinal P-doped Si-poly growth rate evolution

To explain the two last points, which to our knowledge have not yet been put in evidence in the literature, a reference to the chemical mechanism in the reactor is necessary. It is well-known that silane pyrolysis generates manly disilane $\left(\mathrm{Si}_{2} \mathrm{H}_{6}\right)$ and silylene $\left(\mathrm{SiH}_{2}\right)$ in LPCVD conditions (R1 and R2), which are then likely to deposit silicon [11].

$$
\begin{aligned}
& \mathrm{SiH}_{4} \leftrightarrow \mathrm{SiH}_{2}+\mathrm{H}_{2} \\
& \mathrm{SiH}_{2}+\mathrm{SiH}_{4} \leftrightarrow \mathrm{Si}_{2} \mathrm{H}_{6}
\end{aligned}
$$

So, in the entrance zone between the front door and the first wafer, silane is decomposed by thermal pyrolysis into silylene and hydrogen (R1). In the same time, silane and silylene also react together to produce disilane (R2). The concentration of these different chemical species at the end of the entrance zone depending on the volume of this zone, an increase in the distance between the front door and the first wafer allows a more advanced decomposition of the gaseous phase with higher concentrations of disilane and silylene. Furthermore, results of a previous study [12] have suggested that disilane constitutes a source for silylene and is able to produce rapidly this radical by pyrolysis : the quantity of accumulated disilane determines then the average silylene concentration and hence, the contribution of this radical to the deposition of silicon. 
After travelling through the entrance zone and along the wafers load, two possibilities of silylene production in the gas phase are available either from silane decomposition (R1) or from disilane decomposition (R2). As disilane decomposes kinetically faster than silane, the main source of silylene all along the wafers load is disilane. As a result, its high concentration in run corresponding to DEW = $1080 \mathrm{~mm}$, produced in the long entrance zone permits to keep the silicon growth rate along the reactor at a higher value than in run corresponding to $\mathrm{DEW}=100 \mathrm{~mm}$, as put in evidence in Figure 2 . Consequently, the consumption all along the wafers boat of the extra concentration of disilane gives a noticeable decrease in the silicon growth rate from the beginning to the end of the load.

When temperature decreases, the observed phenomena are markedly different, which is consistent with the previous observations. At $560^{\circ} \mathrm{C}$, the order of magnitude of polysilicon growth rate is strongly divided, to reach approximatively $1.4 \AA / \mathrm{min}$. The differences in polysilicon growth rate evolution are unsignificant and are in the range of experimental uncertainties. As a quite remarkable longitudinal uniformity is observed, the influence of the load position seems negligible at low temperatures. Therefore, the homogeneous reactions do not practically occur at low temperature, which is in agreement with the aforementioned explanation.

\section{Modelling principles}

Our previous developments $[9,10]$ led us to the elaboration of a two-dimensional model of LPCVD reactors (CVD2). In this approach, it was assumed that, far from the ends of the wafers line, a large number of phenomena, linked to flow and mass processes, as well as to chemical reactions, must have reached some sort of dynamic equilibrium in a representative part of the reactor constituted by an interwafer spacing and the corresponding annular region between the wafer edge and the reactor walls. This element means that these phenomena repeat periodically from an interwafers region to the following one. Thus, the products of homogeneous-phase silane pyrolysis, i.e. silylene and disilane, are assumed to be in dynamic equilibrium, their consumption being perfectly balanced by their production. A detailed presentation of the modelling principles of CVD2 is presented in $[9,10]$.

But, in the case considered here, the analysis of the experimental data has suggested that a periodicity regime does not necessarily corresponds to actual operating conditions of LPCVD reactors. In what follows, the framework of the new elements introduced in the model will be mentioned :

(i)-For disilane, the periodicity regime assumption is not valid any more as it does not correspond to the explanation suggested for the experimental behavior observed, in which a continuous decrease in disilane concentration along the reactor has been supposed. To take into account this new fact, numerical simulations were performed without assuming the periodicity of disilane concentration. Instead, an average concentration of disilane in the interwafer space was fixed, a high (respectively low) value corresponding to a long (respectively short) entrance zone.

(ii)-The reaction rate of silylene on solid surfaces is assumed to be first-order dependent on silylene concentration :

$$
\mathcal{R}_{\mathrm{SiH}_{2}}=\gamma_{\mathrm{SiH}_{2}} \sqrt{\frac{8 \mathrm{RT}}{\Pi \mathrm{M}_{\mathrm{SiH}_{2}}}} c_{\mathrm{SiH}}
$$

where $\gamma_{S I H 2}$ represents the sticking coefficient of silylene. This coefficient has been taken equal to unity, as suggested by other investigators [11], which is consistent with the very important reactivity of this radical. As silylene reactivity is very high, the assumption of periodical regime has been maintained for this species.

(iii)-The contribution of silane to polysilicon growth rate can be written as function of pure polysilicon deposition rate and of an inhibition factor due to the presence of phosphine :

$$
R_{\mathrm{SiH}_{4} \mathrm{PH}_{3}}=(1-\tau) R_{\mathrm{SiH}_{4}}
$$

An expression of polysilicon growth rate given by Wilke et al.[13] has been adopted after adjusting kinetic constants (see [14] for more precisions).

$$
\mathcal{R}_{\mathrm{SiH}_{4}}=\frac{\mathrm{k} \times 3.210^{-3} \exp \left(\frac{-6800}{\mathrm{~T}}\right) \mathrm{P}_{\mathrm{SiH}_{4}}}{1+4.810^{-8} \exp \left(\frac{10000}{\mathrm{~T}}\right) \mathrm{P}_{\mathrm{H}_{2}}+0.8210^{-10} \exp \left(\frac{180000}{\mathrm{~T}}\right) \mathrm{P}_{\mathrm{SiH}_{4}}}
$$


(iv)-Kinetic data for the homogeneous-phase reactions R1 and R2 can be found in the literature[11]. In this study, the values proposed by Communal et al. [15] computed by a QRRK method have been selected.

\subsection{Computational procedure}

By lack of place, only general principles will be reported :

First, the corrective term $\mathrm{k}$ to be included for the undoped polysilicon deposition was identified and found equal to 0.9 at $620^{\circ} \mathrm{C}$ (respectively 0.88 at $560^{\circ} \mathrm{C}$ ).

Second, depositions performed at low entrance zone length were simulated, since a good longitudinal uniformity was obtained under this condition (see Figure 2), thus suggesting that the periodical regime was obtained. Although the run performed at $620^{\circ} \mathrm{C}$ does not exhibit a perfect uniform longitudinal growth rate evolution for an entrance zone length of $10 \mathrm{~cm}$, it has been nevertheless assumed that the periodical regime is practically obtained for the last wafer of the batch.

The conversion rate of polysilicon between the reactor entrance and the modelling region, necessary for the simulations, was determined from the experimental data.

Model predictions are found to be in agreement with experimental data when the inhibition factor of silane contribution to polysilicon growth rate is equal to $93 \%$ at $620^{\circ} \mathrm{C}$ (respectively $95 \%$ at $560^{\circ} \mathrm{C}$ ) is adopted.

Third, with these elements, the non-periodical behavior was simulated. In this part, as the only difference between the simulations concerning the periodical regime consists in shifting the position of the first wafer of the load, both silane contribution and the inhibition rate due to the presence of phosphine remain unchanged.

Then, the concentration of disilane and its conversion rate were determined by trial and error adjustments to fit with the experimental data.

\subsection{Simulation results}

In presenting the computed results, we sought to select a few significant ones, which should demonstrate the validity of our assumptions.

3.1.1 Disilane concentration: A typical radial profile of disilane concentration is displayed in Figure 3. The concentration, which is approximately independant of position, increases with the entrance zone length. Other simulations have also brought out that this concentration increases strongly with temperature.

The axial profile of disilane concentration in the annular region is presented in Figure 4. Its examination reveals that the disilane concentration increases with the length of the entrance zone and decreases from the entrance to the exit of the modelling region. At high temperature, this concentration increases strongly when the entrance region length is increased and is practically unchanged at low temperature. It can be thus deduced that disilane is more rapidly produced in the entrance region of the reactor at high temperature than at low temperature.

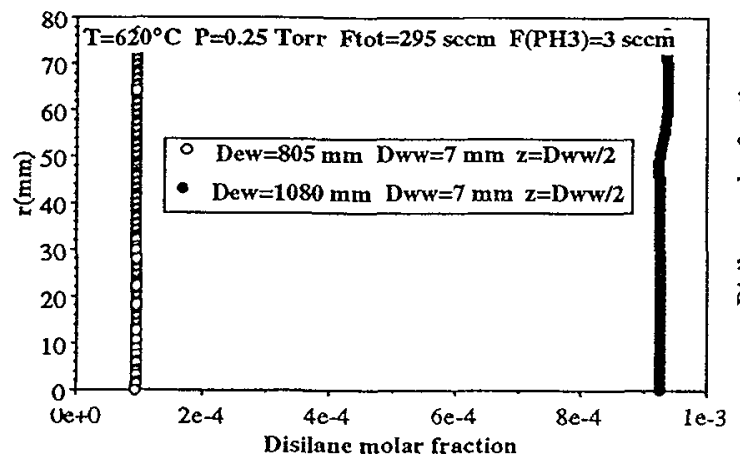

Fig.3: Radial disilane molar fraction $\left(\mathrm{T}=620^{\circ} \mathrm{C}\right)$

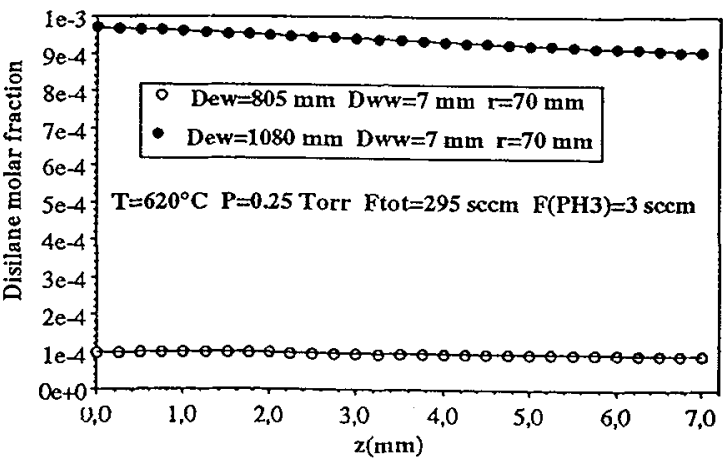

Fig.4 : Axial disilane molar fraction $\left(T=620^{\circ} \mathrm{C}\right)$ 
3.1.2 Polysilicon growth rate: An example of profile of radial polysilicon growth rate is presented in Figures 5(a) and 5(b), where a very good agreement with the experimental data is to be found at the two temperatures and two load positions.

This result partly comes from the parameters adjustment procedure used, - in the central part of the wafers-, but the surprising agreement, at the wafers periphery, in the description of the bull's eye effect supports the validity of the model.
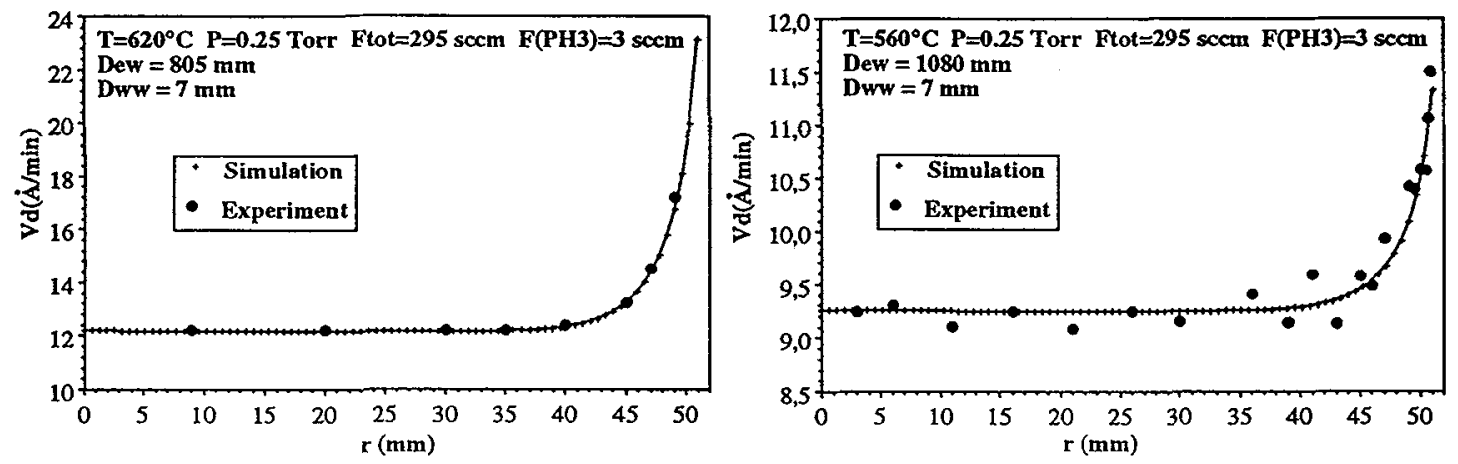

Fig.5(a): Radial polysilicon growth rate profile $\mathrm{T}=620^{\circ} \mathrm{C}$ Fig.5(b): Radial polysilicon growth rate profile $\mathrm{T}=560^{\circ} \mathrm{C}$

\section{Film characterization}

In this part, only the results concerning the depositions runs carried out at high temperature, leading directly to polycrystalline layers will be discussed.

\subsection{Ellipsometry measurements}

Ellipsometry measurements were performed at a wavelength of $405 \mathrm{~nm}$, for which the absorption coefficient of the deposit is high enough to avoid the transmission of the $405 \mathrm{~nm}$ light through the width of the layer.

For pure and phosphorus doped polysilicon depositions (see Figures 6(a) and 6(b)), the results have shown no sensible variation of the optical constants $\mathrm{N}$ and $\mathrm{K}$ when varying the inlet region length.
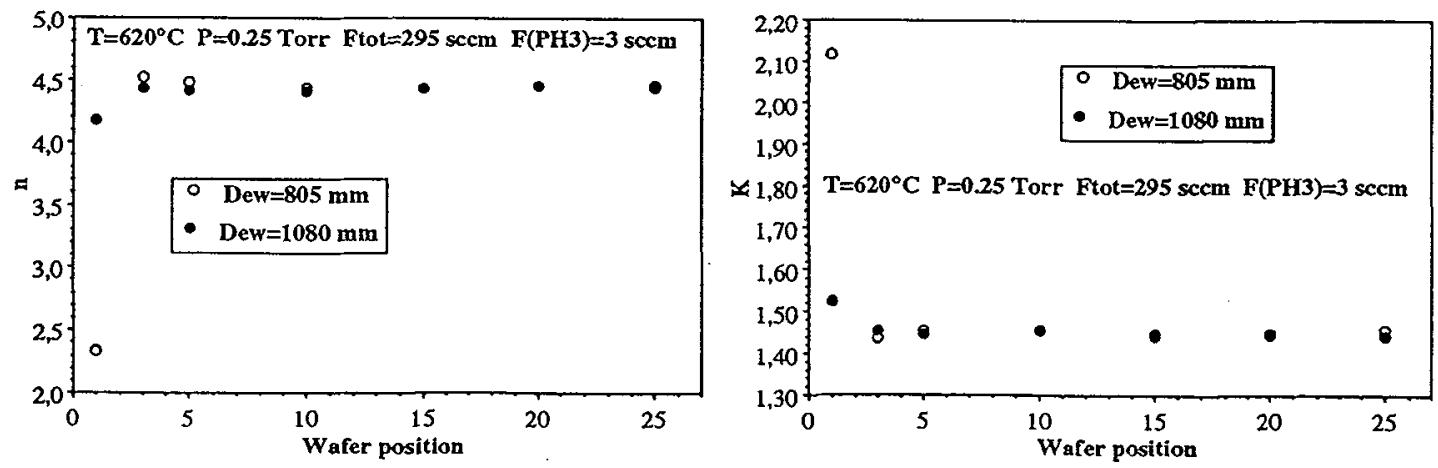

Fig.6(a): Longitudinal evolution of $\mathrm{N}\left(\mathrm{T}=620^{\circ} \mathrm{C}\right) \quad$ Fig. $6(\mathrm{~b})$ : Longitudinal evolution of $\mathrm{K}\left(\mathrm{T}=620^{\circ} \mathrm{C}\right)$ 
Furthermore, for phosphorus doped polysilicon deposition, the values of the optical constants are approximatively similar to those relative to pure polysilicon, suggesting that doping does not infer noticeable variations of these constants.

\subsection{Resistivity measurements}

Resistivity was measured by a four-point probe method at the wafer centre. Figures 7(a) and 7(b) show the longitudinal resistivity evolution for different inlet region lengths. The resistivities ranged from $910^{-3}$ to $1.110^{-2} \Omega . \mathrm{cm}$, which is consistent with the results of other investigators [8].

At $620^{\circ} \mathrm{C}$, the following features are to be observed :

- An increase of the empty inlet section involves a decrease in resistivity.

- When the boat is next to the entrance door, the resistivity homogeneity is not satisfactory.

- Resistivity increases along the load and its variation slows down when the inlet section length

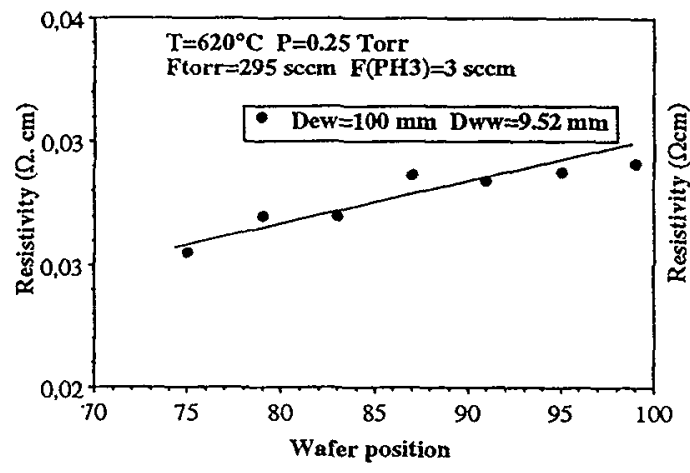

Fig.7(a): Longitudinal evolution of resistivity $\left(\mathrm{T}=620^{\circ} \mathrm{C}\right)$ $620^{\circ} \mathrm{C}$

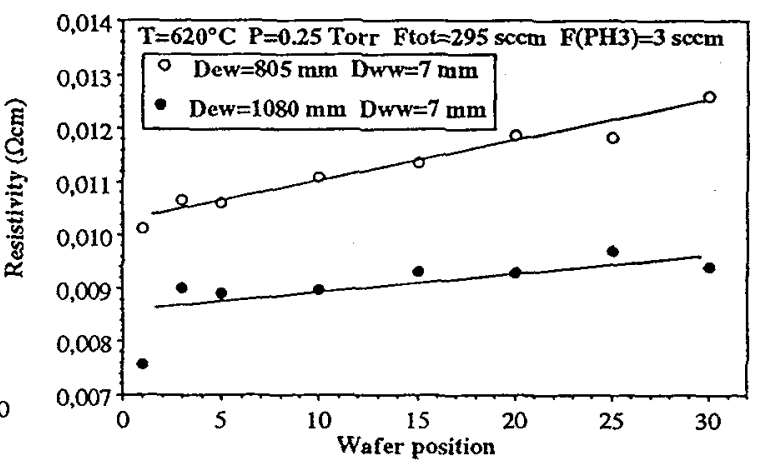

Fig.7(b) : Longitudinal evolution of resistivity $(\mathrm{T}=$

The two last points seem to confirm the importance of homogeneous reactions in the empty section, enhancing the insertion of phosphorus atoms during the layer growth and suggest that a Si-P compound is likely to be formed in gas-phase in this region.

At $560^{\circ} \mathrm{C}$, no influence of the inlet section was to be noted, reinforcing that gas-phase reactions are unimportant at low temperature.

\section{Conclusions and perspectives}

The simultaneous use of experimental analysis and numerical simulation has helped to develop a better understanding of the phenomena involved during in situ phosphonus doped silicon deposition.

Experimentally, this study has recognized the importance of their hot entrance regions, through which silylene and disilane initial concentrations build up. An increase in the entrance zone length entails a more important generation of disilane, allowing consequently to increase the silylene contribution to polysilicon growth rate. It is yet evident that a not very precise control of the load position inside the reactor can involve non negligible growth rate variations, creating irreproducibilities, inadequate for industrial production. This explanation is also likely to account, at least partly, for the discrepancies observed between experimental growth rate results reported by different authors in apparently similar operating conditions. This suggests that if reproducible results are to be obtained at an industrial scale, particularly in the case of in situ phosphorus doped polysilicon deposition, a tight control of the heating elements is required to obtain an identical decomposition of the gaseous mixture in the entrance zone from run to run.

The characterization of the deposited layers has also suggested that a Si-P gaseous species is likely to be formed in this inlet region, and its homogeneous reaction pathway is now under investigation in our laboratory. 
From a modelling point of view, it has been shown that the CVD2 model is a faithful representation of the key features involved during pure and phosphorus doped polysilicon depositions. Particularly in this latter case, it opens up possibilities of finding operating conditions and of designing reactor geometry that will promote more uniform deposition at acceptable growth rate for mass production.

\section{Notations}

\begin{tabular}{|c|c|}
\hline $\mathrm{c}_{\mathrm{SiH} 2}$ & : Silylene concentation [mole $\mathrm{m}^{-3}$ ] \\
\hline DEW & : Distance separating the entrance door of the reactor and the first wafer [mm] \\
\hline Dwe & : Distance separating the last wafer and the exit door of the reactor [mm] \\
\hline Dww & : Interwafer distance $[\mathrm{mm}]$ \\
\hline $\mathrm{M}_{\mathrm{SiH} 2}$ & : Molar mass of silylene [kg] \\
\hline $\mathrm{P}_{\mathrm{H} 2}$ & : Hydrogen partial pressure $[\mathrm{Pa}]$ \\
\hline $\mathrm{P}_{\mathrm{SiH} 4}$ & : Silane partial pressure $[\mathrm{Pa}]$ \\
\hline $\begin{array}{l}\mathrm{r} \\
\mathrm{R}\end{array}$ & : Radial coordinate $[\mathrm{mm}]$ \\
\hline $\mathrm{R}$ & : Gas law constant $\left[\mathrm{kg} \mathrm{m}^{2} \mathrm{~s}^{-2} \mathrm{~mole}^{-1} \mathrm{~K}^{-1}\right]$ \\
\hline $\boldsymbol{R}_{\mathrm{SiH} 4}$ & : Contribution of silane to pure polysilicon growth rate [mole $\mathrm{Si} \mathrm{m}^{-2} \mathrm{~s}^{-1}$ ] \\
\hline $\mathcal{R}_{\mathrm{SiH} 4, \mathrm{PH} 3}$ & $\begin{array}{l}\text { : Contribution of silane to polysilicon growth rate in presence of phosphine } \\
\text { [mole Si } \mathrm{m}^{-2} \mathrm{~s}^{-1} \text { ] }\end{array}$ \\
\hline $\begin{array}{l}R_{S i H 2} \\
\mathrm{~T} \\
\mathrm{z}\end{array}$ & $\begin{array}{l}\text { Contribution of silylene to pure polysilicon growth rate }\left[\mathrm{mole} \mathrm{Si} \mathrm{m}^{-2} \mathrm{~s}^{-1}\right] \\
\text { : Temperature }[\mathrm{K}] \\
\text { : Axial coordinate }[\mathrm{mm}]\end{array}$ \\
\hline$\gamma_{\text {SIH2 }}$ & : Silylene sticking coefficient \\
\hline$\tau$ & $\begin{array}{l}\text { : Inhibition factor of silane contribution to polysilicon growth rate in presence of } \\
\text { phosphine }\end{array}$ \\
\hline
\end{tabular}

\section{References}

[1]-Meyerson B.S., Olbricht W., 1984, J. Electrochem. Soc., Vol. 131, p.2361

[2]-Meyerson B.S., Yu M.L., 1984, J. Electrochem. Soc., Vol. 131, p.2367

[3]-Jensen K.F., Hitchman M.L., Ahmed W., 1985, Proceedings EUROCVD V, Upsaala, Sweden, p. 144

[4]-Mulder J.G.M., Eppenga P., Hendriks M., Tong J.E., 1990, J. Electrochem. Soc., Vol. 137 , p. 273

[5]-Middelman S., Yeckel A., 1986, J. Electrochem. Soc., Vol. 133 , p. 1951

[6]-Yeckel A., Middelman S., 1987, J. Electrochem. Soc., Vol. 134, p. 1275

[7]-Yeckel A., Middelman S., 1990, J. Electrochem. Soc., Vol. 137, p. 207

[8]-Mulder J.G.M., Eppenga P., Hendriks M., Tong J.E., 1990, J. Electrochem. Soc., Vol. 137 , p. 273

[9]-Duverneuil P., Couderc J.P., 1992, J.Electrochem. Soc., Vol. 139, p.296

[10]-Azzaro C., Duvemeuil P., Couderc J.P., 1992, J. Electrochem. Soc., Vol. 139, p.305

[11]-Coltrin M.E., Kee R.J., Miller J.A., 1984, J. Electrochem. Soc., Vol. 131, p.425

[12]-Azzaro C., Duvemeuil P., Couderc J.P., 1993, Comments on the influence of the entrance zone in LPCVD reactors for in situ phosphorus doped polysilicon deposition, to be published in Chem. Eng. Sc., Vol.48, p.1915

[13]-Wilke T.E., Turner K.A., Takoudis C.J., 1986, Chem. Eng. Sci., Vol. 41, p. $6 \overline{43}$

[14]-Azzaro C., Duverneuil P., Couderc J.P., 1992, Chem. Eng. Sci., Vol. 47, p. 3827

[15]-Communal F., Thesis of Master of Science (Chem. Eng.), University of Massachussetts,

Sept. 90 